\title{
Mechanisms to Explain Damage Growth in Optical Materials
}

S. G. Demos, M. R. Koslowski, M. Staggs, L. L. Chase, A. Burnham, H. B. Radousky

This article was submitted to the $32^{\text {nd }}$ Annual Symposium on Optical Materials for High Power Lasers,

Boulder, Colorado, October $16-18,2000$

\section{January 10, 2001}

U.S. Department of Energy

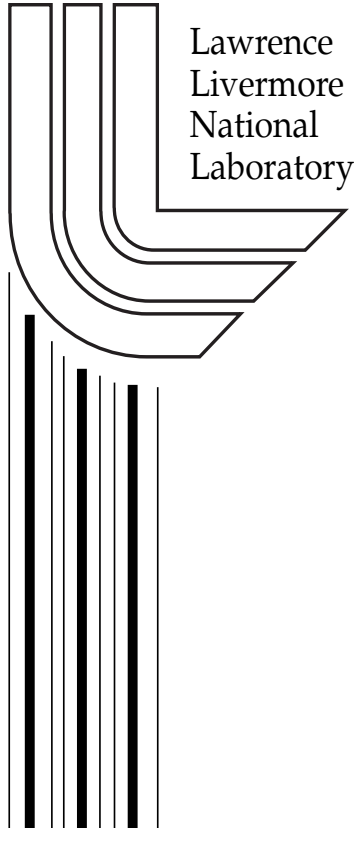




\section{DISCLAIMER}

This document was prepared as an account of work sponsored by an agency of the United States Government. Neither the United States Government nor the University of California nor any of their employees, makes any warranty, express or implied, or assumes any legal liability or responsibility for the accuracy, completeness, or usefulness of any information, apparatus, product, or process disclosed, or represents that its use would not infringe privately owned rights. Reference herein to any specific commercial product, process, or service by trade name, trademark, manufacturer, or otherwise, does not necessarily constitute or imply its endorsement, recommendation, or favoring by the United States Government or the University of California. The views and opinions of authors expressed herein do not necessarily state or reflect those of the United States Government or the University of California, and shall not be used for advertising or product endorsement purposes.

This is a preprint of a paper intended for publication in a journal or proceedings. Since changes may be made before publication, this preprint is made available with the understanding that it will not be cited or reproduced without the permission of the author.

This work was performed under the auspices of the United States Department of Energy by the University of California, Lawrence Livermore National Laboratory under contract No. W-7405-Eng-48.

This report has been reproduced directly from the best available copy.

Available electronically at http://www.doc.gov/bridge

Available for a processing fee to U.S. Department of Energy

And its contractors in paper from

U.S. Department of Energy

Office of Scientific and Technical Information

P.O. Box 62

Oak Ridge, TN 37831-0062

Telephone: (865) 576-8401

Facsimile: (865) 576-5728

E-mail: reports@adonis.osti.gov

Available for the sale to the public from

U.S. Department of Commerce

National Technical Information Service

5285 Port Royal Road

Springfield, VA 22161

Telephone: (800) 553-6847

Facsimile: (703) 605-6900

E-mail: orders@ntis.fedworld.gov

Online ordering: http://www.ntis.gov/ordering.htm

Or

Lawrence Livermore National Laboratory

Technical Information Department's Digital Library

http://www.llnl.gov/tid/Library.html 


\title{
Mechanisms to explain damage growth in optical materials
}

\author{
S. G. Demos", M. R. Kozlowski, M. Staggs, L. L. Chase, A. Burnham, H. B. Radousky \\ Lawrence Livermore National Laboratory, PO Box 808, L-411, Livermore, CA 94551
}

\begin{abstract}
Damage growth in optical materials used in large aperture laser systems is an issue of great importance when determining component lifetime and therefore cost of operation. Understanding the mechanisms and photophysical processes associated with damage growth are important in order to devise mitigation techniques. In this work we examined plasma-modified material and cracks for their correlation to damage growth on fused silica and DKDP samples. We employ an in-situ damage testing optical microscope that allows the acquisition of light scattering and fluorescence images of the area of interest prior to, and following exposure to a high fluence, 355-nm, 3-ns laser pulse. In addition, high-resolution images of the damage event are recorded using the associated plasma emission. Experimental results indicate that both aforementioned features can initiate plasma formation at fluences as low as $2 \mathrm{~J} / \mathrm{cm}^{2}$. The intensity of the recorded plasma emission remains low for fluences up to approximately 5 $\mathrm{J} / \mathrm{cm}^{2}$ but rapidly increases thereafter. Based on the experimental results, we propose as possible mechanisms leading to damage growth the initiation of avalanche ionization by defects at the damage modified material and presence of field intensification due to cracks.
\end{abstract}

Keywords: $\mathrm{SiO}_{2}$, KDP, DKDP, laser damage, optical breakdown

\section{INTRODUCTION}

The presence of laser induced damage in optical materials is responsible for losses in the transmission of laser light arising from enhanced scattering and/or absorption and macroscopic changes in the material integrity. It is believed that laser-induced damage is associated with either absorption in opaque inclusions or by photoionization followed by avalanche ionization, which creates a dense absorbing plasma ${ }^{1-7}$. Damage growth is a key issue for large aperture laser systems such as $\mathrm{NIF}^{8}$. For 355-nm, 3-ns laser irradiation, the problem emerges for fluences higher than $\approx 5 \mathrm{~J} / \mathrm{cm}^{2}$. Small surface damage sites initiated by some surface imperfection start growing in size. This effect is observed in DKDP nonlinear crystals and $\mathrm{SiO}_{2}$ optical elements. Fig. 1 demonstrates the damage growth process on a NIF-size fused silica plate. Small damage sites shown fig. 1a generated during the first pulse grow very fast to the size shown in fig. $1 \mathrm{~b}$ after subsequent exposure to 38 laser pulses. As a result, the beam obscuration level exceeds specifications within a small number of laser pulses making the optical component unusable. This problem can be addressed by avoiding damage initiation or by applying a damage mitigation process to preclude further growth at damage sites.
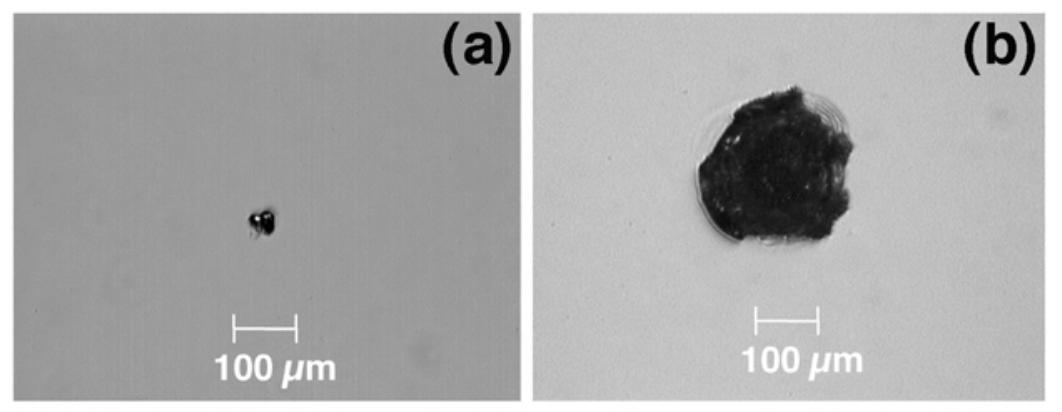

Figure 1: Images of the same damage site on a NIF-size fused silica plate a) following initiation with one pulse and b) after 38 pulses. 
It was recently shown that the laser damage process is accompanied by material modifications ${ }^{9,10}$. The presence of a characteristic emission under 351-nm CW excitation suggests the formation of defects at the damage site for both DKDP and $\mathrm{SiO}_{2}$. The behavior of these defects under high-power laser irradiation may be critical in understanding damage growth. These defects can yield the starting electrons, which result in avalanche ionization early during the laser pulse. This can lead to plasma re-ignition and further material modifications. One may expect that there will always be some damage initiators on the surface of a large optic to produce a number of damage sites. In order to devise successful damage mitigation procedures, it is important to understand the mechanisms governing damage growth.

The objective of this work is to investigate the damage growth process. We are utilizing an in-situ damage testing fluorescence microscope, which monitors the plasma re-ignition process by acquiring images using the characteristic plasma emission during damage. This is then correlated using light scattering and fluorescence imaging to defect formations and/or cracks at laser induced damage sites.

\section{EXPERIMENTAL SETUP}

The microscopic fluorescence imaging and in-situ damage testing apparatus is shown in fig. 2. The imaging system used in this investigation is composed of $\mathrm{X} 10$ microscope objective followed by a X5 magnification zoom lens. The images were recorded using a liquid nitrogen cooled CCD detector. Optical filters positioned between the $\mathrm{CCD}$ and the zoom lens were used in order to record images of a $1.2 \times 1.2 \mathrm{~mm}^{2}$ section of the sample in the 450-1000-nm spectral region. Three types of images are recorded. First, a white light source illuminates the sample and the light scattering (bright field) image of the surface is recorded. Fluorescence images of the area of the sample under investigation were also recorded using a $\mathrm{CW}$ Argon ion laser operating at $351-\mathrm{nm}$ as the photoexcitation source. A $400 \times 600 \mu \mathrm{m}^{2}$ section of the sample imaged as described

above was exposed to the third harmonic of a

\footnotetext{
fluorescence microscope
}

a 3-ns pulse-width, Q-switched, Nd:YAG laser. Beam diagnostics incorporated into the system allowed for accurate measurement of the laser fluence. The laser fluence at the sample's surface could be set up to $25 \mathrm{~J} / \mathrm{cm}^{2}$. The characteristic plasma emission observed during damage was utilized in order to record images of that event as it happens and correlate the location of plasma formation to preexisting features observed with light scattering and fluorescence imaging.

The experiments were performed on polished fused silica and diamond turned fast-grown DKDP crystals. All sample surfaces were flat. The experiments were performed with the sample held at room temperature.

\section{RESULTS}

Figure 3 shows images depicting the evolution of plasma re-ignition on a DKDP surface damage site as a function of the fluence of subsequent 355-nm, 3-ns laser pulses. Using the microscopic fluorescence imaging system, images were recorded at the middle of the crater of the damage site. Fig. 3a shows a light scattering image of the crater where the modified material caused by the laser-induced damage process can be easily located using fluorescence microscopy. As previously reported, the crater of damage sites in KDP (and DKDP) crystals exhibits a broad emission under $351-\mathrm{nm}$ excitation centered at $\approx 520-\mathrm{nm}$. This emission was assigned to defects that are generated as the results of the extreme conditions that the material is exposed during the damage process. The 
section of the sample that is later exposed to $355-\mathrm{nm}$ pulses irradiation is also shown in fig. 3a as a broken-line ellipse (1/ $\mathrm{e}^{2}$ intensity contour) covering an area approximately $600 \mathrm{X} 400 \mu \mathrm{m}^{2}$ with a near Gaussian spatial intensity distribution. Fig. $3 \mathrm{~b}$ shows a plasma emission within the damage site while under exposure at $1.9 \pm 0.4 \mathrm{~J} / \mathrm{cm}^{2}$. This image shows the presence of emission at localized sites within the laser damaged area having diameter of the order of $10 \mu \mathrm{m}$. The observed emission is attributed to formation of plasma although this process is still not well understood. Figs. 3c, 3d, 3e, and $3 \mathrm{f}$ show the plasma emission images when the sample was irradiated with increasing laser fluences of $2.9 \pm 0.6,3.9 \pm 0.8,5 \pm 1$, and $7.5 \pm 1.5 \mathrm{~J} / \mathrm{cm}^{2}$, respectively. The experiments indicate that plasma is formed while under exposure to low fluences that are well below the damage growth threshold. As the laser fluence increases, the number of sites where plasma is formed increases accompanied by an increase in the intensity of the plasma emission. At fluences that reach the damage growth threshold, the number of "re-ignited" sites becomes so large that they merge to a large event covering most, if not all of the irradiated section of the damage site. This observation was repeatable using different damage sites and different samples. For example, using $\approx 2 \mathrm{~J} / \mathrm{cm}^{2}$ irradiation, the number of sites where plasma is formed within the damage crater remains small although different sites may "re-ignite" from pulse to pulse. The result of such small events is not visible in the light scattering image, but it may be visible in the fluorescence image, where an increase in the emission intensity may be observed at the location where plasma was formed. For higher laser fluences leading to larger plasma re-ignition events, changes in the light scattering as well as in the fluorescence images are observed.
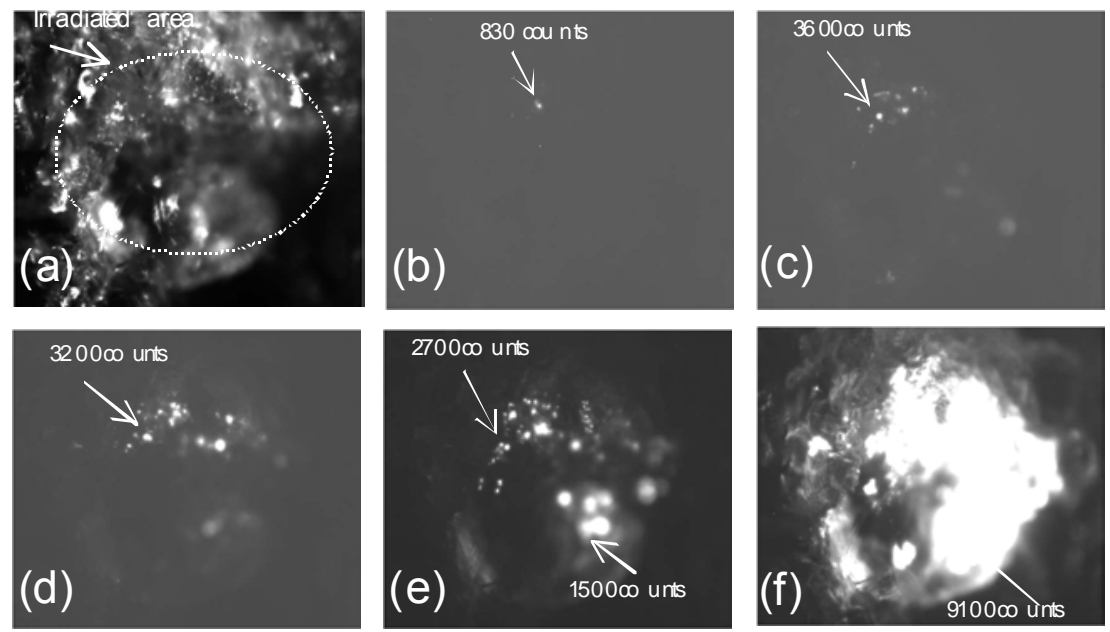

Figure 3: a) A light scattering image of the crater of a DKDP surface damage site. Plasma emission images under 355-nm, 3-ns irradiation at b) $1.9 \pm 0.4$, c) $2.9 \pm 0.6$, d) $3.9 \pm 0.8$, e) $5 \pm 1$, f) $7.5 \pm 1.5 \mathrm{~J} / \mathrm{cm}^{2}$, respectively

Plasma re-ignition within damage sites for laser fluences as low as $2 \mathrm{~J} / \mathrm{cm}^{2}$ was also observed in $\mathrm{SiO}_{2}$ samples. The behavior of the plasma formation in $\mathrm{SiO}_{2}$ surface damage craters was found to be very similar to that observed in DKDP. The intensity of the plasma emission increases as a function of the laser fluence. A more quantitative measure of the plasma re-ignition process is presented in fig. 4 where the integrated emission in the imaged area is plotted as a function of the laser fluence for both, DKDP (fig. 4a) and $\mathrm{SiO}_{2}$ (fig. 4b) surface damage sites. The experimental results indicate that for both materials, plasma emission appears at fluences as low as 2 $\mathrm{J} / \mathrm{cm}^{2}$, and its intensity remains very low for fluences up to $\approx 5 \mathrm{~J} / \mathrm{cm}^{2}$, beyond which it rapidly increases. The low intensity part of the curve is associated with the generation of small in size plasma spots. Above $5 \mathrm{~J} / \mathrm{cm}^{2}$ the number of ignition sites increases, and they eventually merge to form larger sites. It is significant that damage growth is observed at fluences of 5-7 J/ $\mathrm{cm}^{2}$, which is about the same level that the plasma emission becomes intense and large in size plasma formations are observed.

Mechanical damage is usually observed at laser induced damage sites and includes crushed, stressed and cracked material. Field intensification arising from cracks has been proposed as a mechanism to initiate material breakdown. This concept was tested in $\mathrm{SiO}_{2}$ samples that were mechanically damaged using laser peening. This process produced cracks without the formation of the modified containing defects that is present at laser induced damage sites. Experiments were then performed to study the behavior of these cracks under high fluence laser irradiation. Fig. 5a shows the image of a crack located $\approx 500 \mu \mathrm{m}$ below the surface of the sample. The image was 

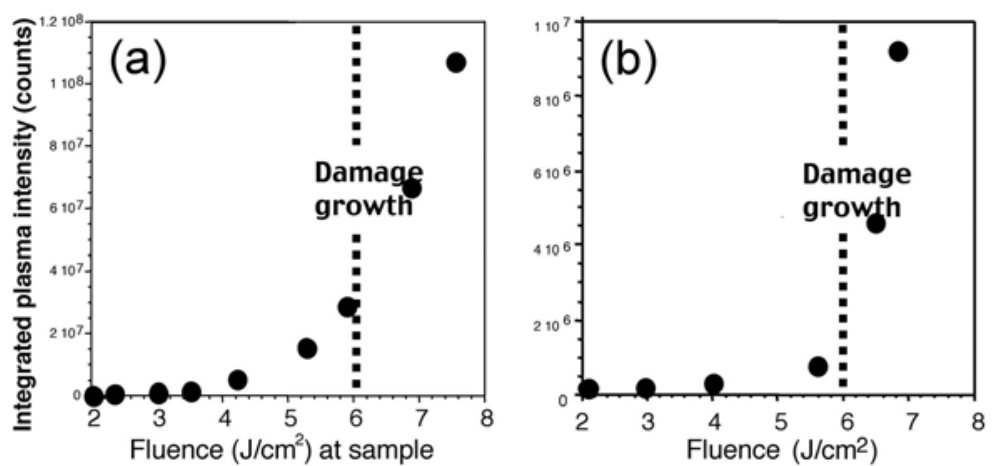

Figure 4: Integrated plasma emission intensity from DKDP (a) and $\mathrm{SiO}_{2}$ (b) surface damage sites as a function of the laser fluence.

Figure 5: a) Image of the crack in the bulk of a $\mathrm{SiO}_{2}$ sample. b) Plasma emission image during irradiation with a pulse at $\approx 2.2$ $\mathrm{J} / \mathrm{cm}^{2}$ followed by c) a second pulse at $5.3 \mathrm{~J} / \mathrm{cm}^{2}$. d) Fluorescence image under 351-nm CW excitation. e) Plasma image during exposure of this site to another pulse at $\approx 5.3 \mathrm{~J} / \mathrm{cm}^{2}$. f) Fluorescence image following irradiation with 23 pulses at $\approx 5.2 \mathrm{~J} / \mathrm{cm}^{2}$.

recorded through the rear surface of the sample that was not exposed to laser peening. This crack was then exposed to 355 -nm laser irradiation. Fig. $5 \mathrm{~b}$ shows the plasma emission image during irradiation with a pulse at $\approx 2.2 \mathrm{~J} / \mathrm{cm}^{2}$ showing the formation of plasma. The same sample was subsequently exposed to a second pulse at $5.3 \mathrm{~J} / \mathrm{cm}^{2}$. The plasma emission image recorded during exposure to the second pulse is shown in fig. 5c. This image indicates plasma formation in multiple locations near the crack. The changes in the material arising from the two pulses and plasma formation ware visible in both, the light scattering image and in the fluorescence image under $351-\mathrm{nm} \mathrm{CW}$ excitation which is shown in fig. 5d. The later image reveals the presence of optical emission from modified material at the locations where plasma was formed. After exposure of this site to another pulse of the same energy $\left(\approx 5.3 \mathrm{~J} / \mathrm{cm}^{2}\right)$, the plasma image shown in fig. 5e indicates that the same sites where plasma was formed previously (during the second pulse) "re-ignite". This process repeats under irradiation with additional laser pulses of similar fluences. Fig. $5 \mathrm{f}$ shows the fluorescence image of the sample following irradiation with 23 pulses at $\approx 5.2 \mathrm{~J} / \mathrm{cm}^{2}$. This image indicates the formation of a large volume of modified emissive material due to plasma formation. This observation indicates that the emissive modified material is responsible for the continuation of the process since the original favorable geometric condition for field enhancement was removed following plasma formation and melting of the material at this site. 
The critical role that cracks can play for the growth (or initiation) of damage sites due to field enhancement ${ }^{11}$ is best depicted in fig. 6 where the result of high fluence laser irradiation on two intersecting cracks is imaged. This crack configuration can create interference and high field intensity spots in the bulk caused by constructive interference of light reflected off of crack surfaces. This will give rise to breakdown and plasma formation in the bulk near the cracks. Fig. 6a shows the image of the intersecting crack before irradiation while fig. $6 \mathrm{~b}$ shows the fluorescence image following exposure to two pulses at $\approx 10.5 \mathrm{~J} / \mathrm{cm}^{2}$. The later image shows the presence of emissive modified material at isolated sites in the bulk. Assuming that there were no bulk damage precursors $^{12,13}$ (which is the case for the bulk of this material since, damage is observed predominantly on the surface), the only explanation for this result is material breakdown due to field enhancement by the cracks.
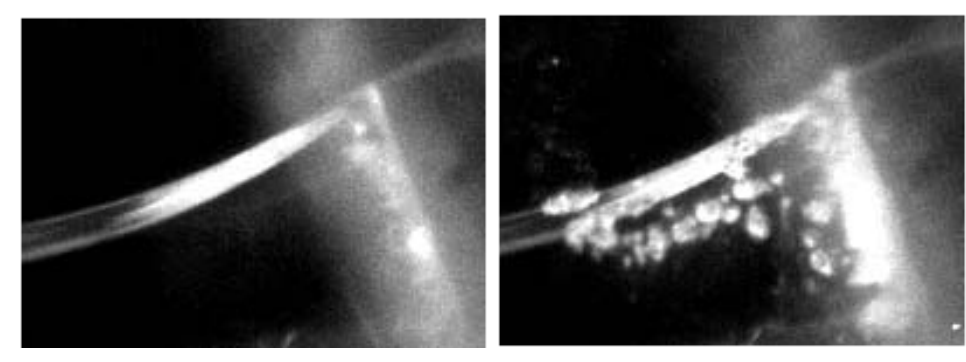

Figure 6: a) Image of two intersecting cracks before irradiation. b) Fluorescence image following exposure to two pulses at $\approx 10.5 \mathrm{~J} / \mathrm{cm}^{2}$. The later image shows the presence of emissive modified material at isolated sites in the bulk.

\section{DISCUSSION.}

The experimental results indicate that for lower laser fluences, the number of sites that exhibit plasma emission decreases with cutoff fluence at $\approx 2 \mathrm{~J} / \mathrm{cm}^{2}$. For higher laser fluences, the number and the emission intensity of the sites where plasma is formed increase while their size also expands. For fluences $5-7 \mathrm{~J} / \mathrm{cm}^{2}$, the process evolves into a large event covering large parts of the irradiated area when damage growth is observed. This indicates that the plasma formation event which is accompanied by heating and the generation of a pressure wave is the cause for damage growth. At high fluences this event can be large enough to create stress sufficient to cause mechanical failure of the adjacent material and expand the size of the damage crater. At lower fluences, although plasma is formed, the energy deposited is not sufficient to cause mechanical failure of the material. This result suggests that monitoring for isolated plasma formation under low fluences laser irradiation can reveal the weakness and tendency of a damage site to grow under high fluence irradiation. This method may be useful for the evaluation or monitoring of damage sites that are treated using some type of damage mitigation procedure without the need to be exposed to high fluence irradiation.

The fact that practically all of the irradiated section of the damage site re-ignites for fluences of $\approx 7 \mathrm{~J} / \mathrm{cm}^{2}$ indicates that this fluence is associated with an avalanche ionization threshold due to defects in the modified material leading to plasma formation. The observation of plasma within the damage crater for fluences as low as 2 $\mathrm{J} / \mathrm{cm}^{2}$ may be attributed to absorption and avalanche ionization by the modified material in combination with moderate field enhancement at these locations arising from geometrical features. However, a larger concentration of defects may also lead to plasma formation at lower fluences by providing the starting electrons to reach the critical plasma density of $10^{18}-10^{21}$ electrons $/ \mathrm{cm}^{3}$.

Sub-surface cracks can cause plasma "ignition" at very low laser fluences. Field enhancement in the presence of surface defects on the crack may be the driving mechanism. However, field enhancement may be sufficient to cause intrinsic breakdown of the material as demonstrated in fig. 6. Following plasma formation at cracks, highly emissive material is formed with the characteristic spectral profile of the modified material at surface laser induced damage sites. The cracks studied in this work that were produced using laser peening are arguably similar in width to those created during laser induced damage since both are the result of a pressure wave originating on the surface. It is therefore important for the implementation of a successful damage mitigation process ${ }^{14-16}$ that the cracks be removed from the damage site. 


\section{CONCLUSION.}

In an effort to better understand the damage growth process, we have studied the interaction of high fluence, $355-\mathrm{nm}$ pulsed irradiation with damage sites in fused silica and DKDP samples. The experimental results strongly suggest that the absorbing modified layer as well as the mechanically modified material including the cracks and crushed material can re-ignite the damage process. Once the damage re-ignition process begins, it will evolve at a similar rate that new initiation sites evolve and grow under subsequent laser irradiation

\section{ACKNOWLEDGEMENT}

This work was performed under the auspices of the U.S. Department of Energy by the University of California, Lawrence Livermore National Laboratory under contract No. W-7405-Eng-48.

\section{REFERENCES}

1. 1 N. Bloembergen, Laser induced electric breakdown in solids, IEEE J. of Quantum Electr., 10, 375, 1974

2. W. L. Smith, Laser induced breakdown in optical materials, Optic. Engin. 17, 489, 1978

3. S. C. Jones, P. Braunlich, R. T. Casper, X. A. Shen, Recent progress on laser-induced modifications and intrinsic bulk damage of wide-gap optical matrials, , Optic. Engin. 28, 1039, 1989.

4. L. L. Chase, Laser ablation and optical surface damage, Springer Series in Material science, Vol. 28, Laser Ablation, J. C. Miller, Ed., Sprringer-Verlag, Berlin, 1994.

5. B. C. Stuart, M. D. Feit, A. M. Rubenchik, B. W. Shore and M. D. Perry, Nanosecond-to-femptosecond laser induced breakdown in dielectrics, Phys. Rev. B, 53, 1749, 1996.

6. P. Braunlich, S. C. Jones, X. A. Shen, and R. T. Casper, Laser-induced modifications and the mechanism of intrinsic damage in wide-gap optical materials, Nuclear Instruments \& Methods In Physics Research Section B, 46, 224, 1990

7. N. Bloembergen, "Role of cracks, pores, and absorbing inclusions on laser induced damage threshold at surfaces of transparent dielectrics", Applied Optics 12, 661-664 (1973).

8. E. M. Campbell, Fusion Technology, 26, 755 (1994).

9. M. R. Kozlowski, C. L. Battersby, S. G. Demos, "Luminescence Investigation of $\mathrm{SiO}_{2}$ Surfaces Damaged by $0.35 \mathrm{~mm}$ Laser Illumination", G. J. Exarhos, A. H. Guenther, M. R. Kozlowski, K. L. Lewis, M. J. Soileau, Eds., SPIE, 3902, 138-143, 1999.

10. S. G. Demos, M. Staggs and H. B. Radousky, "Damage induced material modification in the bulk KDP crystals", G. J. Exarhos, A. H. Guenther, M. R. Kozlowski, K. L. Lewis, M. J. Soileau, Eds., SPIE, 3902, 428432, 1999.

11. F. Y Genin, A. Salleo, T. V. Pistor, and L. L. Chase, "Role of light intensification by cracks in optical breakdown on surfaces", submitted for publication in Applied Optics

12. R. A. House, J. R. Bettis, and A. H. Guenther, "Correlation of laser-induced damage with surface structure and preparation techniques of several optical glasses at $1.06 \mu \mathrm{m}$ ", Laser-Induced Damage in Optical Materials, NBS-SP vol. 462, 305-320, (1976).

13. D. W. Camp, M. R. Kozlowski, L. M. Sheehan, M. A. Nichols, M. Dovik, R. G. Raether, and I. M. Thomas, "Subsurface damage and polishing compound affect the 355-nm laser damage threshold of fused silica surfaces", Laser-Induced Damage in Optical Materials, SPIE vol. 3244, 356-364, (1998).

14. P. A. Temple, D. Milam, and W. H. Lowdermilk, " $\mathrm{CO}_{2}$-laser polishing of fused silica surfaces for increased laser damage resistance at $1.06 \mu \mathrm{m}$ ”, Laser-Induced Damage in Optical Materials, NBS-SP vol. 620, 229-236, (1980).

15. T. Kamimura, K. Nakai, M. Yoshimura, Y. Mori, T. Sasaki, M. Tanaka, Y. Okada, H. Yoshida, M. Nakatsuka, T. Kojima, and K. Yoshida, "High damage resistivity of optical surface for UV lasers by ion beam etching", Review of Laser Engineering 27, 623-627 (1999).

16. L. W. Hrubesh, M. A. Norton, W. A. Molander, P. J. Wegner, M. Staggs, S. G. Demos, J. A. Britten, L. J. Summers, E. F. Lindsey, and M.R. Kozlowski, "Chemical etch effects on laser-induced surface damage growth in fused silica", XXXII Annual symposium on optical materials for high power lasers, Boulder, Colorado, October 16-18, 2000. 